\title{
Effect of Preheating on the Mechanical Properties of Resin Composites
}

\author{
Mine Betül Uctaslia \\ Hacer Deniz Arisu ${ }^{b}$ \\ Lippo VJ Lasillac \\ Pekka K. Valittu ${ }^{d}$
}

\begin{abstract}
Objectives: The purpose of this study was to compare the flexural strength and modulus of two commercial resin composites, at room temperature and 40,45 and $50^{\circ} \mathrm{C}$ prior to light polymerization with standard and step-cure protocols.

Methods: One nanohybrid (Grandio, VOCO, Cuxhaven, Germany), and microhybrid composite resin (Filtek Z250, 3M ESPE, St. Paul, MN, USA) were used. The materials were inserted into rectangular moulds at room temperature or preheated to a temperature of 40,45 or $50^{\circ} \mathrm{C}$ and cured with standard or step-cure protocols with high intensity halogen (Elipar Highlight, 3M-ESPE, St. Paul, MN, USA). Ten specimens were prepared for each preheating and light curing protocol. A three-point bending test was performed using a universal testing machine at a crosshead speed of $1 \mathrm{~mm} / \mathrm{min}$. The data were analyzed by one-way analysis of variance and Tukey's post hoc tests $(P<.05)$ to examine the effect of curing protocol and preheating. Pearson's correlation test was used to determine the correlation between tested mechanical properties and preheating.

Results: There were no statistically significant difference between tested mechanical properties of the materials, curing protocols and temperature of the materials. No significant correlation was found between preheating and tested mechanical properties.

Conclusions: The mechanical properties of the tested materials did not changed by preheating so the tested materials could be preheated because of the other potential clinical advantages like more adaptation to the cavity walls. (Eur J Dent 2008;2:263-268)
\end{abstract}

Key words: Resin composite; Preheating; Polymerization.

- assistant Professor, University of Gazi, Faculty of Dentistry, Department of Operative Dentistry \& Endodontics, Turkey.

b Lecturer, University of Gazi, Faculty of Dentistry, Department of Operative Dentistry \& Endodontics, Turkey.

Professor, University of Turku, Institude of Dentistry, Department of Prosthetic Dentistry \& Biomaterial Science, Finland.
Professor, University of Turku, Institude of Dentistry, Department of Prosthetic Dentistry \& Biomaterial Science, Finland.

Corresponding author: Hacer Deniz Arisu University of Gazi, Faculty of Dentistry,

Department of Operative Dentistry \& Endodontics 8. Cadde 82. Sokak 06510 Emek-Ankara / Turkey

Tel: +903122034123

Fax: +90 3122239226

E-mail: hdenz@yahoo.com, hacer@gazi.edu.tr 


\section{INTRODUCTION}

The use of resin composites for restoring posterior stress-bearing cavities has increased significantly in recent years. As an alternative to amalgam, the early attempts to apply resin composites in posterior teeth had only limited success because of insufficient material properties. ${ }^{1}$ Improvements in the properties of the materials together with their positive clinical performances encourage continuously the use of posterior resin composites as a viable alternative to amalgam. ${ }^{2}$ The mechanical properties of resin-based composite mainly depend on its microstructure and composition. The micro structural characteristics involve the type, size and quantity of filler particles. These characteristics are directly related to the composition of the composite. ${ }^{3}$

One of the primary concerns is adaptation (both internal and marginal) and the resulting interfacial seal of resin composite to the preparation walls. When placing and contouring a composite, a clinician often has difficulty to adapt the material to the cavity preparation because of the paste's high viscosity. Unlike amalgam, highly filled composite resins cannot be "condensed" by using a heavier force to reduce porosity or to enhance adaptation. ${ }^{3-5}$ To decrease wear and polymerization shrinkage in posterior applications, resin composite manufacturers increased filler content. However, this modification results in higher paste viscosity. ${ }^{6,7}$ Furthermore, many contemporary resin composites are also sticky and difficult to manipulate, resulting in greater problems in placement. ${ }^{3}$ Freedman ${ }^{8}$ and Friedman 9 claimed that warming resin based restorative materials prior to placement and contouring enhances composite adaptation to preparation walls by increasing the viscosity of unpolymerized resin composite paste. The extent of viscosity change may be attributed to many factors: resin composition, filler content and shape. ${ }^{10-12}$ Thus because of the wide variety in chemistry and composition of resin composites currently used, a great variation in the viscosity of these materials in response to evaluated temperatures may be expected. ${ }^{3}$ An additional advantage of heating the resin composite prior to placement and polymerizing is the accompanying increase in monomer conversion. ${ }^{13-17}$ With increased paste temperature, free radicals and propagating polymer chains become more mobile as a result of decreased paste viscosity and react to a greater extent, resulting in a more complete polymerization reaction and greater crosslinking. The increase in polymerization may lead to improved mechanical properties and increased wear resistance. ${ }^{13,16,17}$

Fractures within the body of restorations and at the margins have been cited as a major problem regarding the failure of posterior resin composites. ${ }^{18}$ The fracture related material properties, such as fracture resistance, elasticity, and the marginal degradation of materials under stress have usually been evaluated by the determination of the material parameters such as flexural strength and flexural modulus. ${ }^{19}$

The aim of this in vitro study was to assess the flexural strength and flexural modulus of two resin composites prepared at room temperature or preheated to a temperature of 40,45 or $50^{\circ} \mathrm{C}$.

\section{MATERIALS AND METHODS}

One nanohybrid (Grandio, VOCO, Cuxhaven, Germanyl, and a microhybrid resin composite (Filtek Z250, 3M ESPE, St. Paul, MN, USA) were used. The materials were inserted into rectangular moulds with the dimensions specified by the ISO 4049/2000 specification ( $25 \mathrm{~mm} \times 2 \mathrm{~mm}$ $x 2 \mathrm{~mm}$ ) at room temperature (RT) or preheated to a temperature of 40,45 or $50^{\circ} \mathrm{C}$ with EASE-IT composite softener (Ronvig Dental, Daugaard, Denmark). Then the specimens were cured with standard $\left(700 \mathrm{~mW} / \mathrm{cm}^{2}\right.$ for $\left.40 \mathrm{sec}\right)$ or step-cure (150-180 mW/cm² for $10 \mathrm{sec}$ and 650-700 mW/ $\mathrm{cm} 2$ for $30 \mathrm{sec}$ ) modes of high intensity halogen (Elipar Highlight, 3M ESPE, St. Paul, MN, USA) light curing unit. Ten specimens were prepared for each preheating and light curing protocol.

The mould was positioned over a glass slide and a mylar strip and the resin composite was inserted as a single increment. Another mylar strip was positioned and pressed against it with a glass slide for excess removal before polymerization. The excess of material in the corner was carefully removed with a scalpel blade. A three-point bending test was performed using a universal testing machine (Lloyd LRX; Lloyd Instruments 
Ltd, Fareham Hants, UK) at a crosshead speed of $1 \mathrm{~mm} / \mathrm{min}$. The maximum loads were obtained and the flexural strength $(\sigma)$ was calculated in megapascals (MPa) by using the following formula:

\section{$\sigma=3 \mathrm{FL} /\left(2 \mathrm{BH}^{2}\right)$}

Where $F$ is the maximum load (in newtons); $L$ is the distance between the supports (in millimeters); $B$ is the width of the specimen (in millimeters) and $\mathrm{H}$ is the height (in millimeters).

The modulus of elasticity (GPa) was determined as:

\section{$\mathrm{E}=\mathrm{FL}^{3} / 4 \mathrm{BH}^{3} \mathrm{~d}$}

Where $F$ is the maximum load; $L$ is the distance between the supports; $B$ is the width of the specimen; $\mathrm{H}$ is the height of the specimen, and $\mathrm{d}$ is the deflection (in millimeters) corresponding to the load $F$.

The data were analyzed by one-way analysis of variance and the differences between materials, curing and preheating protocols were assessed with Tukey HSD tests $(P=0.05)$ to determine the effect of material, curing and preheating protocols (SPSS 15.0 version, SPSS Inc., Chicago, USA). Pearson's correlation test was used to examine the correlation between mechanical properties (flexural strength and flexural modulus) and preheating.

\section{RESULTS}

Table 2 summarizes the mean values and standard deviations of the tested groups. While there were no statistically significant differences between flexural strengths of the tested materials for curing and preheating protocols $(P=0.299)$, there were statistically significant differences between the flexural modulus of the tested groups $(P<.001)$. The flexural modulus values of $Z 250$ showed significant differences between room temperature and preheated to $40^{\circ} \mathrm{C}(\mathrm{P}=0.009)$ and, between preheated to $45^{\circ} \mathrm{C}$ and $50^{\circ} \mathrm{C}(\mathrm{P}<.001)$ at standard curing mode. Flexural modulus values of Grandio were significantly higher than Z250 for all the curing protocols and tested temperatures. No significant correlation was found between preheating and tested mechanical properties [flexural strength $(P=0.174)$ and flexural modulus $(P=0.486)$ of the materials.

\section{DISCUSSION}

Preheating resin systems prior to photopolymerization have many potential advantages like increasing the degree of conversion, ${ }^{16,20}$ increasing the surface hardness. ${ }^{21}$ Previous studies have showed that preheating increased the flow and enhance the adaptation of the resin to the prepared tooth walls and, thus, potentially reduced microleakage. ${ }^{20}$ Flow of commercial resin composites could be increased by preheating. ${ }^{22}$ The overall extent and rate of monomer conversion in resin systems cured at higher temperatures are better than that performed at room temperature. . $^{4,16}$ In recent studies a significant increase in conversion were observed upon preheating. ${ }^{15-17,23}$

In clinical situations when the resin composite is preheated, the temperature of the resin composite could affect the pulp tissue when it is placed in the cavity but with the time delay between dispensing it from the syringe and placing it into the preparation a significant decrease occurs. ${ }^{23}$ Daronch et $\mathrm{al}^{24}$ found no significant differences in the intrapulpal temperatures between either room temperature or preheated resin composite at similar restorative stages. In another study, Daronch et $\mathrm{al}^{25}$ concluded that the resin composite temperature decreased rapidly upon compile removal from the heating device.

Flexural strength and modulus are meaningful

Table 1. Materials used in this study.

\begin{tabular}{|c|c|c|c|c|c|c|c|}
\hline Material & Type & $\begin{array}{l}\text { Organic } \\
\text { matrix }\end{array}$ & Inorganic filler & $\begin{array}{l}\text { Filler } \\
\% \text { wt }\end{array}$ & $\begin{array}{l}\text { Filler } \\
\% \text { vol }\end{array}$ & $\begin{array}{c}\text { Batch } \\
\text { Number }\end{array}$ & Shade \\
\hline $\begin{array}{l}\text { Grandio } \\
\text { (Voco, Cuxhaven, } \\
\text { Germany) }\end{array}$ & $\begin{array}{l}\text { Nanohybrid } \\
\text { composite } \\
\text { resin }\end{array}$ & $\begin{array}{l}\text { TEGMA, } \\
\text { BIS-GMA }\end{array}$ & $\begin{array}{c}\text { Spherical nanoparticles } \\
\text { of silicon dioxide } \\
0.02-0.05 \text {, size-matched } \\
\text { vitro ceramics }\end{array}$ & 87 & 71.4 & \#531919 & A 3,5 \\
\hline $\begin{array}{l}\text { Filtek Z250 } \\
\text { (3M ESPE, } \\
\text { St. Paul, Minn, USA) }\end{array}$ & $\begin{array}{l}\text { Microhybrid } \\
\text { composite } \\
\text { resin }\end{array}$ & $\begin{array}{l}\text { BIS-GMA, } \\
\text { UDMA, } \\
\text { BIS-EMA }\end{array}$ & $\begin{array}{c}\text { Circonium-silicon } \\
\text { particles } 0.01-3.5 \\
\text { (average: } 0.6 \text { ) }\end{array}$ & 78 & 61 & \#20050104 & A 3,5 \\
\hline
\end{tabular}


mechanical properties for brittle materials, although the results cannot be extrapolated to the clinical behavior without considering some aspects, namely flaw distribution ${ }^{26}$ and structural reliability of the material. ${ }^{27}$ Nonetheless, the in vitro threepoint bending flexural test is recommended by the ISO 4049/200028 specification for polymer based materials and is widely used for comparative purposes..$^{29,30}$

An optimal tooth restoration material should mimic structural, mechanical and physical characteristics of dentin and enamel. ${ }^{31} \mathrm{Xu}$ et al ${ }^{32}$ measured the elastic modulus of human enamel and dentin and obtained a mean value of $19 \mathrm{GPa}$ for the dentin. Young's modulus of enamel was 94 Gpa while depending significantly on tooth orientation. The mechanical properties of all the resin composites tested in this study either at room temperature or preheated, are far from those of enamel. However, nanohybrid resin composite had similar flexural modulus (16.83-20.12 GPa) to flexural modulus of dentin.

Filler content, filler size and the distribution of the filler particles were determined to highly influence the physical and mechanical properties of the resin composites. It has been shown that the filler volume fraction and filler load level of the resin composites correlate with the material strength and elastic modulus, as well as the fracture toughness of the material. ${ }^{33-38} \mathrm{Kim}$ et $\mathrm{al}^{39}$ found out that the mechanical properties of the resin composites are related to their filler content. Resin composites with the highest by volume exhibited the highest flexural strength and flexural modulus. In the present study, no significant difference were found between flexural strengths of the groups, but microhybrid resin composite had higher flexural strength values than nanohybrid resin composite at all tested temperatures. However, there were significant differences between the flexural modulus of two materials in all the tested temperatures and curing protocols. The nanohybrid resin composite had significantly higher flexural modulus values than microhybrid resin composite with both curing protocols and all tested temperatures. This result is in agreement with Beun et $\mathrm{al}^{40}$ who reported that the nanohybrid resin composite has higher elastic modulus while the universal hybrid resin composite has higher flexural strength.

Table 2. Mean values and standard deviations of the tested groups. The same superscript letters indicate no significant difference between groups (Tukey HSD test, $\alpha=0,05$ ).

\begin{tabular}{|c|c|c|c|c|}
\hline Materials & $\begin{array}{l}\text { Curing } \\
\text { Protocol }\end{array}$ & Temperature & $\begin{array}{c}\text { Flexural } \\
\text { Strength (MPa) }\end{array}$ & $\begin{array}{l}\text { Flexural modulus } \\
\text { (GPa) }\end{array}$ \\
\hline \multirow{5}{*}{ Grandio (VOCO, Cuxhaven, Germany) } & \multirow{5}{*}{ Standard cure } & $\mathrm{RT}$ & $143( \pm 10)^{\text {a }}$ & $18.16( \pm 1.79)$ abcd \\
\hline & & 40 & $144( \pm 27)$ a & $18.84( \pm 2.72)^{b c d}$ \\
\hline & & 45 & $151( \pm 13)^{\text {a }}$ & $19.93( \pm 2.03)^{d}$ \\
\hline & & 50 & $146( \pm 14)^{\text {a }}$ & $19.71( \pm 1.95)^{\text {cd }}$ \\
\hline & & RT & $149( \pm 10)^{\text {a }}$ & $16.83( \pm 2.02)$ abcde \\
\hline \multirow{11}{*}{ Filtek Z250 (3M ESPE, St. Paul, MN, USA) } & \multirow{3}{*}{ Step cure } & 40 & $150( \pm 20)$ a & $19.62( \pm 4.23) \mathrm{cd}$ \\
\hline & & 45 & $149( \pm 13)$ a & $20.12( \pm 4.08)^{d}$ \\
\hline & & 50 & $159( \pm 9)$ a & $18.90( \pm 2.17) \mathrm{cd}$ \\
\hline & \multirow{5}{*}{ Standard cure } & RT & $152( \pm 11)$ a & $13.71( \pm 1.22)$ ef \\
\hline & & 40 & $159( \pm 19)$ a & $16.13( \pm 2.34)$ abce \\
\hline & & 45 & $150( \pm 26)^{\text {a }}$ & $14.64( \pm 1.57)$ aef \\
\hline & & 50 & $157( \pm 25)$ a & $12.43( \pm 0.82)^{f}$ \\
\hline & & RT & $158( \pm 16)$ a & $13.52( \pm 1.97)$ ef \\
\hline & \multirow{3}{*}{ Step cure } & 40 & $144( \pm 23)$ a & $15.24( \pm 3.00)$ abef \\
\hline & & 45 & $146( \pm 17)$ a & $13.81( \pm 0.88)$ ef \\
\hline & & 50 & $166( \pm 26)^{\text {a }}$ & $13.90( \pm 0.95)$ ef \\
\hline
\end{tabular}


No significant correlations were found between the flexural strength and preheating and also between the flexural modulus and preheating of the tested materials. When microhybrid resin composite (Z250) was cured with standard curing protocols, the flexural modulus was significantly higher when the resin composite material was preheated to a temperature of $40^{\circ} \mathrm{C}$. However there were no significant differences in the other curing protocols. Also there were no significant differences between the curing protocols and between the temperatures for nanohybrid resin composite.

The present study assessed the limited mechanical effects of preheating resin composites. Further research is needed for evaluating the effects of preheating on the other mechanical properties and on pulp tissue.

\section{CONCLUSIONS}

The results of this study showed preheating and different curing protocols did not have any harmful effect on the mechanical properties of the tested materials. So it could be concluded that these materials could be preheated because of the other potential clinical advantages like more adaptation to the cavity walls.

\section{REFERENCES}

1. Manhart J, Kunzelmann KH, Chen HY, Hickel R. Mechanical properties and wear behavior of light cured packable composite resins. Dent Mater 2000;16:33-40.

2. Poss SD. Using a new condensable composite for posterior restorations. Compend Contin Educ Dent Suppl 1999;23:1418.

3. Al-Sharaa KA, Watts DC. Stickiness prior to some light cured resin composites. Dent Mater 2003;19:182-187.

4. Blalock JS, Holmes RG, Rueggeberg FA. Effect of temperature on unpolymerized composite resin film thickness. J Prosthet Dent 2006;96:424-432.

5. Rodrigues Junior SA, Zanchi CH, Carvalho RV, Demarco FF. Flexural strength and modulus of elasticity of different types of resin based composites. Braz Oral Res 2007;21:1621.

6. Crim G, Chapman KW. Reducing microleakage in Class II restorations: an in vitro study. Quintessence Int 1994;25:781785.
7. Schuckar M, Geurtsen W. Proximo-cervical adaptation of Class II composite restorations after thermocycling: a quantitative and qualitative study. J Oral Rehabil 1997;24:766-775.

8. Freedman PD. Clinical benefits of pre-warmed composites. Private Dent 2003;8:111-114.

9. Friedman J. Thermally assisted polymerization of composite resins. Contemp Esthetics Rest Practice 2003; 7:46.

10. Roeters JJ, Shortall AC, Opdam NJ. Can a single composite resin serve all purposes? Br Dent J 2005;199:73-79.

11. Powers JM, Wataha JC. Dental materials: properties and manipulation. St. Louis: Elsevier, 2003;68-72.

12. Hervas-Garcia A, Martinez-Lozano Ma, Cabanes-Vila J, Barjau-Escribano A, Fos-Galve P. Composite resins: a review of the materials and clinical indications. Med Oral Patol Oral Cir Bucal 2006;11:E215- 220.

13. Bagis $Y H$, Rueggeberg FA. Effect of post cure temperature and heat duration on monomer conversion of photoactivated dental resin composite. Dent Mater 1997;13:228232.

14. Park SH, Lee CS. The difference in degree of conversion between light-cured and additional heat-cured composites. Oper Dent 1996;21:213-217.

15. Trujillo M, Newman SM, Stransbury J. Use of near-IR to monitor the influence of external heating on dental composite photopolymerization. Dent Mater 2004;20:766777.

16. Daronch M, Rueggeberg FA, De Goes MF. Monomer conversion of pre-heated composite. JDent Res 2005;84:663667.

17. Daronch M, Rueggeberg FA, De Goes MF, Giudici R. Polymerization kinetics of pre-heated composite. $J$ Dent Res 2006;85:38-43.

18. Roulet JF. The problems associated with substituting composite resins for amalgam: a status report on posterior composites. J Dent 1988;16:101-113.

19. Craig RG. Restorative dental materials. St. Louis: Mosby Publishing Co, 1997.

20. Lovell LG, Lu H, Elliott JE, Bowman CN. Understanding the kinetics and network formation of dimethacrilate dental resins. Polym Adv Technol 2001;12:335-345.

21. Muñoz CA, Bond PR, Sy-Muñoz J, Tan D, Peterson J. Effect of pre-heating on depth of cure and surface hardness of light-polymerized resin composites. Am J Dent 2008;21:215222.

22. Lovell LG, Lu H, Elliot JE, Stansbury JW, Bowman CN. The effect of cure rate on the mechanical properties of dental resins. Dent Mater 2001;17:504-511. 
23. Prasanna N, Pallavi Reddy Y, Kavitha S, Lakshmi Narayanan $\mathrm{L}$. Degree of conversion and residual stress of preheated and room-temperature composites. Indian $J$ Dent Res 2007;18:173- 176 .

24. Daronch M, Rueggeberg FA, Hall G, De Goes MF. Effect of composite temperature on in vitro intrapulpal temperature rise. Dent Mater 2007;23:1283-1288.

25. Daronch M, Rueggeberg FA, Moss L, De Goes MF. Clinically relevant issues related to preheating composites. $J$ Esthet Restor Dent 2006;18:340-351.

26. Loughran GM, Versluis A, Douglas WH. Evaluation of sub-critical fatigue crack propagation in a restorative composite. Dent Mater 2005;21:252-261.

27. Della Bona A, Anusavice KJ, DeHoff PH. Weibull analysis and flexural strength of hot-pressed core and veneered ceramic structures. Dent Mater 2003;19:662-669.

28. International Organization for Standardization ISO 4049/ 2000-Dentistry-Polymer-based filling, restorative and luting materials Switzerland: ISO; 2000.

29. Chung SM, Yap AUJ, Chandra SP, Lim CT. Flexural strength of dental composite restoratives: comparison of biaxial and three-point bending test. $J$ Biomed Mater Res B Appl Biomater 2004;71:278-283.

30. Palin WM, Fleming GJ, Marquis PM. The reliability of standardized flexure strength testing procedures for a light-activated resin-based composite. Dent Mater 2005;21:911-919.

31. Sabbagh J, Vreven J, Leloup G. Dynamic and static moduli of elasticity of resin-based materials. Dent Mater 2002;18:6471.

32. Xu HHK, Smith DT, Jahamir S, Romberg E, Kelly JR, Thompson VP, Rekow ED. Indentation damage and mechanical properties of human enamel and dentin. J Dent Res 1998;77:472-480.

33. St Germain H, Swartz ML, Phillips RW, Moore BK, Roberts TA. Properties of microfilled composite resins as influenced by filler content. J Dent Res 1985;64:155-160.

34. Li Y, Swartz ML, Phillips RW, Moore BK, Roberts TA. Effect of filler content and size on properties of composites. $J$ Dent Res 1985;64:1396-1401.

35. Braem M, Finger WJ, Van Doren VE, Lambrechts $P$, Vanherle G. Mechanical properties and filler fraction of dental composites. Dent Mater 1989;5:346-349.

36. Chung $\mathrm{KH}$. The relationship between composition and properties of posterior resin composites. J Dent Res 1990;69:852-856.

37. Chung $\mathrm{KH}$, Greener EH. Correlation between degree of conversion, filler concentration and mechanical properties of posterior composite resins. J Oral Rehabil 1990;17:487494.
38. Gladys S, Van MB, Braem M, Lambrechts P, Vanherle G. Comparative physico-mechanical characterization of new hybrid restorative materials with conventional glassionomer and resin composite restorative materials. $J$ Dent Res 1997;76:883-894.

39. Kim KH, Ong JL, Okuna O. The effect of filler loading and morphology on the mechanical properties of contemporary composites. J Prosthet Dent 2002;87:642-649.

40. Beun S, Glorieux T, Devaux J, Vreven J, Leloup G. Characterization of nanofilled compared to universal and microfilled composites. Dent Mater 2007;23:51-59. 